\title{
Transforaminal Nerve Roots Steroid Injections Versus Pulsed Radiofrequency Application For Treatment of Chronic Low Back Pain
}

\author{
Ahemed Elsied Abd El Rahman, Ahmed Helmy Abou Elsoud, Ekramy Mansour \\ Abdelghafar and Ayman Mohamed Mohamed Abd Elkareem
}

\begin{abstract}
Objectives: This study aims to Compare the Effectivenesses of transforaminal epidural steroid injection (TFESI) for the Nerve Roots Steroid Injections Versus Pulsed Radiofrequency Application For Treatment of Chronic Low Back Pain

Patients and methods: The study, which was conducted between September 2013 and September 2016, included 40 patients with low back pain (13 males, 27 females; median age 45 years; [min. 22 - max. 88 years]). All injections were applied under Carm fluoroscopy guidance, using a mix of methyprdnisone and macain. The valuation parameters are pain evaluation pre and post the procedure ( $2 \mathrm{hrs}$ after the procedure , 1st week ,after one month and after 3 months from the procedure) the pain evaluation by visual analoge scale (0-10) and low back pain questionare also consumption of analgesic drugs is compared pre and post procedure. Reporting of possible complications

Results: As regard pain scores for both groups group there was significant decrease in VAS score in both groups from the preprocedure score $(\mathrm{P}$-value $<0.001)$. Patients in group 1 had less VAS scores in comparison for group 2 (P-value=0.005). also There was significant decrease in LBP score in both groups from the preprocedure score $(\mathrm{P}-$ value $<0.001$ ). Patients in group 1 had less LBP score in comparison for group 2 (Pvalue $<0.001$ ).

Conclusion: In this study, we aimed to present the effectiveness Of Transforaminal Nerve Roots Steroid Injections Versus Pulsed Radiofrequency Application For Treatment of Chronic Low Back Pain. We found that there was significant decrease in VAS score in both groups from the pre procedure score. Patients in TFESI group had less VAS and low back pain scores in comparison for PRF group, and application of PRF is more safe than steroid injection
\end{abstract}

Keywords: Pulsed Radiofrequency Treatment; Transforaminal Epidural Steroid Injection; Radicular Pain

\section{Introduction}

Chronic Lumbo-Sacral radicular pain is the most common neuropathic pain; its annual prevalence among general populations is about 10 to $25 \%$. LSR pain commonly affects sciatic nerve and lower lumber nerve roots and is mainly caused by herniation of one or more of lumbar or sacral intervertebral discs, hypertrophied bulging ligments, epidural adhesion after spine surgeries. The lifetime incidence of this condition is estimated to be between $13 \%$ and
$40 \%$. The condition has the potential to become chronic and intractable, with major socio-economic implications (Merskey and Bokdu, 1994). It could be proposed that radicular pain in sciatic nerve roots arises from a complex interaction of inflammatory, immune, and pressure related elements (Brisby et al., 2002).

Chronic lumbar radicular pain (CLR) refers to symptoms of neuropathic pain in the territory of the affected lumbar nerve root. More precisely, the 
pathology in this condition affects a particular nerve root after it exists from the spinal canal, and before it becomes a part of the somatic nerve. The quality of this pain is usually sharp, lancinating, or burning. Clear distinction must be made between radicular pain (as described above) and radiculopathy. Radiculopathy refers to objective loss of sensory and/or motor function as a result of conduction block and leads to features of numbness, motor loss, wasting, weakness, and loss of reflexes ( Govind J., 2004 ) .

The pathophysiology of radicular pain is complex, with mechanical inflammatory, and immunological factors playing a role (Thelander U. et al. 1992; McCarron RF, et al. 1987 ; Olmarker K, et al. 1995). The dorsal root ganglion (DRG) has been implicated in its pathogenesis by giving rise to sustained impulse transmission as a result of direct compression or as a site of hyperexcited structure. Prolonged compression presumably accompanied by pathological changes in the nerve root or DRG causes radicular pain to develop ( Barnsley L., 2002)). The majority of patients with acute radicular pain due to a symptomatic herniated disc improve with conservative or no treatment and have minimal pain by 3 months, However a minority (less than 5\%) go on to suffer from significant chronic pain. Radicular pain is mostly treated trial of bed rest, medications, physiotherapy, and epidural steroid injections (ESI) (Saal JA., 1990).

Farrar et al reported that Intervertebral disc herniation is the most common cause of LBP followed by failed back surgery syndrome (FBSS) that affects $20 \%$ to $40 \%$ of the patients who underwent lumbar surgery each year, (Farrar et al.,
2001) and spinal stenosis (SS) a common cause of pain and functional limitations in the elderly (Van Zundert et al., 2005). In our study, there are many patients who were suffering from chronic back pain for various reasons. Herniated disc and FBSS were the commonest cases, about $85 \%$ of them. Most of them were on medical treatment for long period such as pregabalin, gabapentin, tricyclic antide-pressant, opioids and NSAIDs. These medications failed to relieve their pain completely

Historically, epidural steroid injections (ESIs) have been used as an adjunct in the treatment of radicular pain ( Lee HM et al. 1998) since the early reports, success rates ranging from $20 \%$ to $100 \%$ (average, 67\%) have been documented. However, the efficacy of ESI has lasted, on the average less than 3 months. These disparate results can be explained by several methodological and technical flaws. The inclusion criteria generated a patient population with mixed pathologies (intervertebral disc herniation, spinal stenosis, spondylolisthesis, postsurgical changes). Also, the epidural injections, both the caudal and translaminar types, were performed without the use of fluoroscopy or contrast. In effect, they were performed blindly. Epidural injections performed in this manner are known to miss the perceived target area $30 \%$ to $40 \%$ of the time (Weinstein SM et al., 1998 ).

ESI, although effective in reducing short-term pain in most patients, is associated with side effects such as headaches, flushing, water retention, metabolic and endocrine changes like glucose intolerance, and adrenal suppression. They are also known to be associated with potentially serious side effects such as spinal cord infarction and death secondary to intra-arterial injection of particulate steroid 
preparations. It is clinically imperative and beneficial to look for alternate interventions which could be effective with fewer and/or lesser side effects (Kushnerik V. et al., 2009 ; Benedetti E, et al. 2009 ).

Fluoroscopic guidance with contrast enhancement ensures that a high concentration of medication reaches the disc nerve interface (Renfrew DL et al., 1991). Traditional translaminar and caudal epidural injection routes are dorsal, and corticosteroid spread to the ventral target site occurs by diffusion. Additionally, the dorsal median epidural septum may confine the spread of dorsal epidural flow to the side ipsilateral to the injection. Consequently, it seems improbable that an adequate concentration of corticosteroid could be delivered to the target tissues by traditional caudal or translaminar approaches with or without the use of fluoroscopic guidance.( O'Neill C et al., 1999)

The lumbar transforaminal ESI (TFESI) technique using fluoroscopic control allows a high concentration of corticosteroid to be delivered precisely to this target site (i.e., the ventral aspect of the lumbar nerve root sleeve and the dorsal aspect of the disc herniation (Derby R. et al., 1993).

Steroids are powerful antiinflammatory agents, and effectively reduce nerve root inflammation produced by disc herniation or a disc pathology near the epidural space. An initial observational study reported transforaminal epidural steroid injection (TFESI) offered a treatment option for radicular pain due to lumbar disc herniation and that it provided > $50 \%$ pain reduction in $75 \%$ of treated patients (Vad VB et al., 2002).

Cooper and others stated that when conservative therapies prove inadequate, invasive therapies may be tried including the epidural administration of corticosteroids. The level of evidence in managing LBP with epidural steroids is strong for short-term relief but limited for longterm relief (Cooper et al., 2004). Geurts and colleagues concluded that there were no significant differences between 2 methods of treatment regarding to adverse events and complications, and no serious complications or side effects arose in either selective epidural or PRF patients(Geurts et al., 2003).also Geurts and others in their trial did not show a significant difference in treatment effect between lumbosacral radiofrequency treatment of dorsal root ganglia and control treatment. Consequently, the use of this type of radiofrequency lesioning as routine treatment in lumbosacral radicular pain should not be advocated. (Geurts et al., 2003).

The idea of Pulsed Radiofrequency (PRF) was spawned after a chance meeting in 1993, and the first PRF procedure on a lumbar dorsal root ganglion, took place on February 1996 ( Cosman, 2005, Sluijter, 2005, Sluijter and van Kleef, 2007). Since then, there had been reports that it has been successfully used for the treatment of myriad pain conditions.

The Three major analgesic mechanisms have been proposed to explain the effect of PRF. Firstly, it may change the transmission of pain signals in the dorsal horn by activating $\mathrm{C}$-fos gene expression in the superficial lamina (Y. Higuchi et al., 2002) and decreasing glial cell activation. Secondly, it can induce endogenous opioid release by increasing Met-enkephalin levels. Finally, as the effect of PRFL is reversed by serotonin and alphaadrenergic antagonists, it might work by facilitating descending inhibitory pain pathways. These mechanisms may explain the delayed effect of the PRF (Van Boxem K.et al., 2010). 
SOHAG MEDICAL JOURNAL Transforaminal Nerve Roots Steroid Injections Versus Pulsed

All of the results in this study were reported as prospective, randomized, controlled, to assess the difference in pain relief and improvement functional disabilities with selective Nerve root steroid injection and PRF on DRG in patients who affected by CBP with radicular pain. The results confirmed that there is a statistical difference between the two groups .

\section{Results}

Forty patients have participated in this study with twenty patients in each group. Their demographic characteristics showed no significant difference between study groups as shown in table () and Figures ().

Table(1): Patients demographic characteristics

\begin{tabular}{|c|c|c|c|}
\hline & Group 1 & Group 2 & P-value \\
\hline \multicolumn{4}{|l|}{ Age (year) } \\
\hline $\begin{array}{l}\text { Sex } \\
\text { Males } \\
\text { Females }\end{array}$ & $\begin{array}{l}7(35) \\
13(65)\end{array}$ & $\begin{array}{l}6(30) \\
14(70)\end{array}$ & 0.47 \\
\hline $\begin{array}{l}\text { Previous surgery } \\
\text { Yes } \\
\text { No }\end{array}$ & $\begin{array}{l}5(25) \\
15(75)\end{array}$ & $\begin{array}{l}7(35) \\
13(65)\end{array}$ & 0.49 \\
\hline $\begin{array}{l}\text { Laterality } \\
\text { RT } \\
\text { LT } \\
\text { Bilateral }\end{array}$ & $\begin{array}{l}8(40) \\
12(60) \\
0\end{array}$ & $\begin{array}{l}7(35) \\
11(55) \\
2(10)\end{array}$ & 0.35 \\
\hline
\end{tabular}

Data presented as Mean(Sd), or Number(\%)

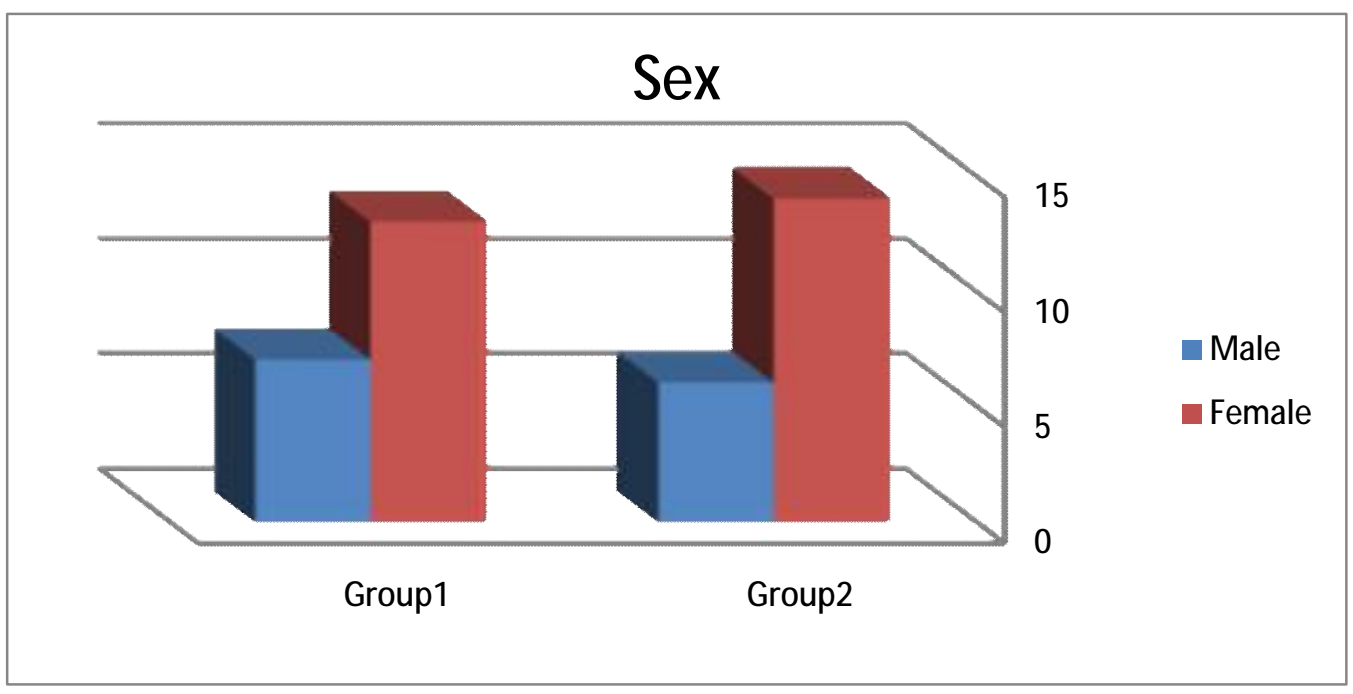

Fig.(1): patients sex in study groups. 
SOHAG MEDICAL JOURNAL Transforaminal Nerve Roots Steroid Injections Versus Pulsed

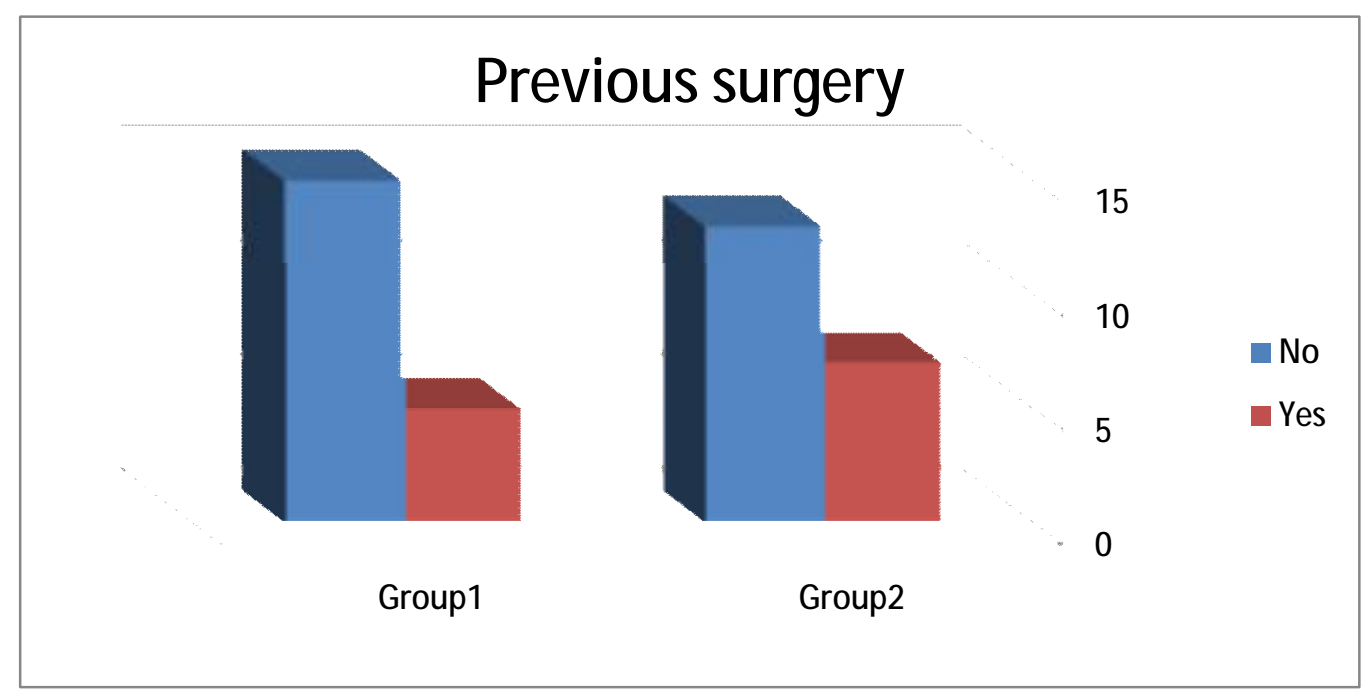

Fig.(2): presence of previous surgery

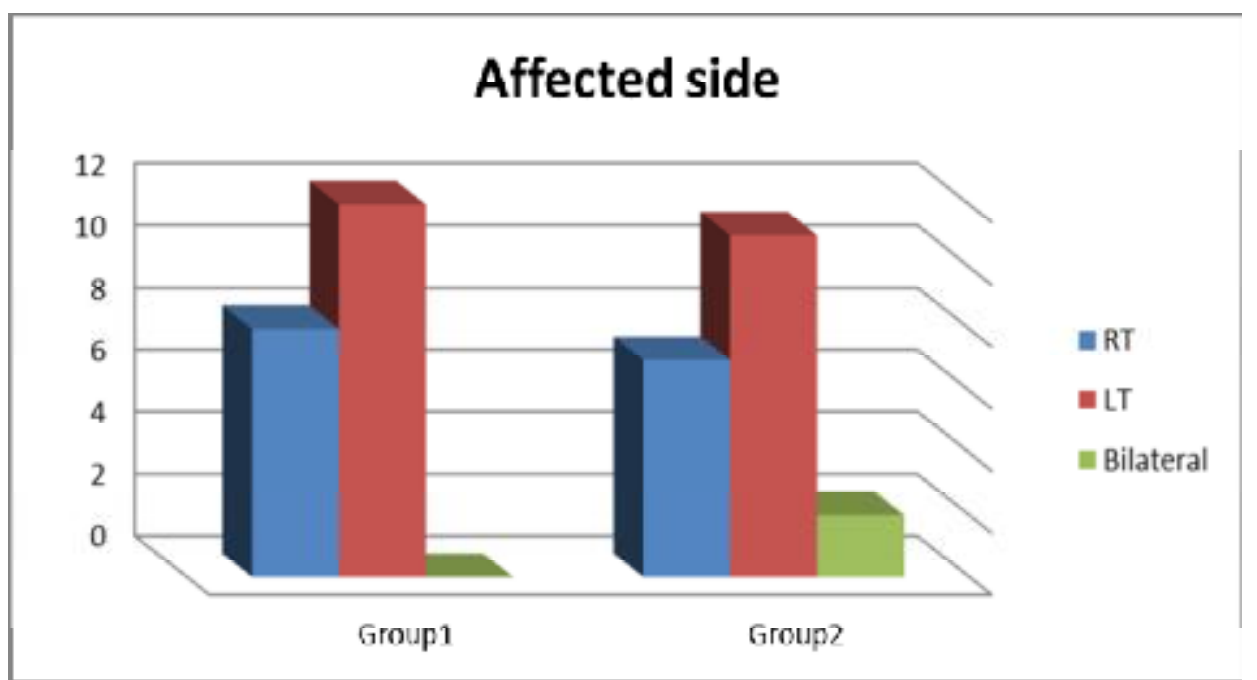

Fig.(3): Affected side in study groups.

VAS:

As shown in Table() and figure(), there was significant decrease in VAS score in both groups from the preprocedure score $(\mathrm{P}$-value $<0.001)$. Patients in group 1 had less VAS scores in comparison for group $2(\mathrm{P}$-value $=0.005)$.

Table(2): VAS score in study groups.

\begin{tabular}{|l|l|l|l|}
\hline & Group 1 & Group 2 & p- value \\
\hline VAS(basal) & $\mathbf{8 . 8 5 ( 0 . 9 9 )}$ & $\mathbf{8 . 9 ( 0 . 8 5 )}$ & $\mathbf{0 . 8 6}$ \\
\hline VAS(2hour) & $\mathbf{6 . 8 ( 1 . 0 5 )}$ & $\mathbf{7 . 3 ( 0 . 8 6 )}$ & $\mathbf{0 . 1 1}$ \\
\hline VAS(1week) & $\mathbf{5 . 9 ( 0 . 8 5 )}$ & $\mathbf{7 . 2 ( 1 . 1 5 )}$ & $0.0002^{*}$ \\
\hline VAS(1month) & $\mathbf{3 . 6 5 ( 1 . 6 3 )}$ & $\mathbf{5 . 5 7 ( 2 . 2 9 )}$ & $\mathbf{0 . 0 0 4}{ }^{*}$ \\
\hline VAS(3month) & $\mathbf{2 ( 1 . 6 5 )}$ & $\mathbf{4 ( 3 . 1 )}$ & $\mathbf{0 . 0 1 5}$ \\
\hline
\end{tabular}

Data presented as Mean(SD). * P-value $<0.05$. 
SOHAG MEDICAL JOURNAL Transforaminal Nerve Roots Steroid Injections Versus Pulsed

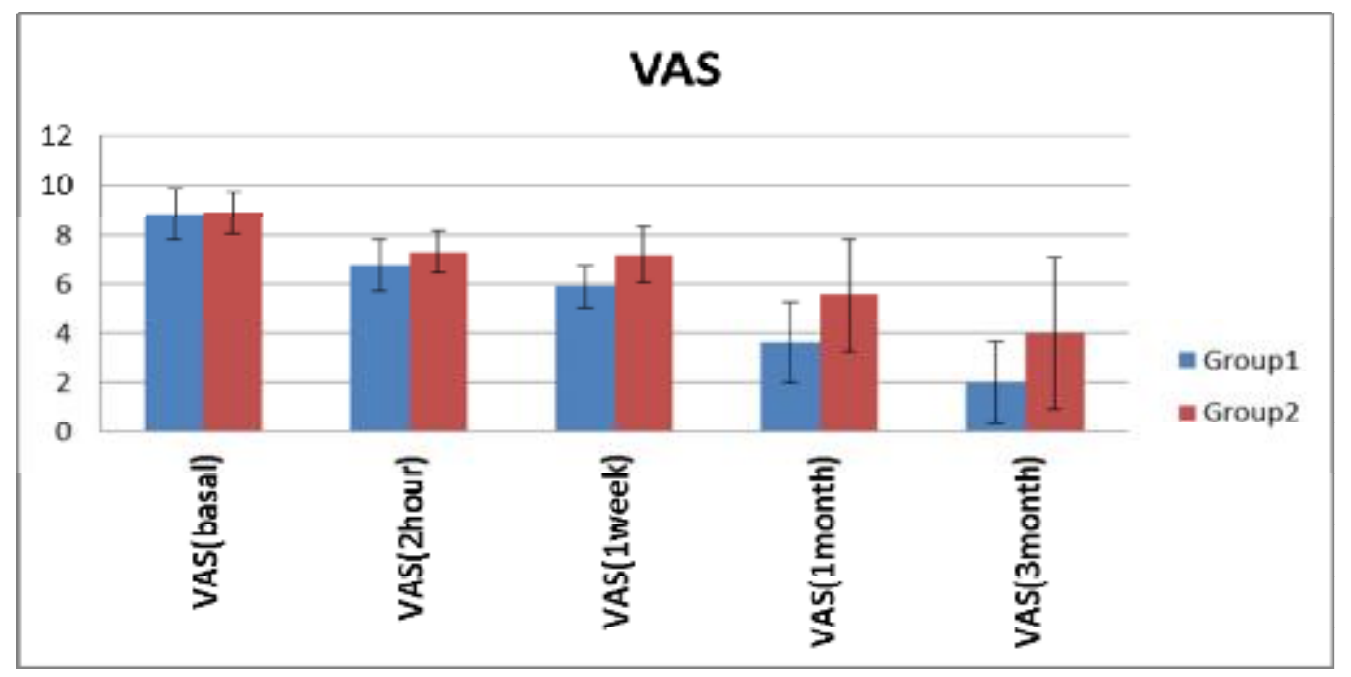

\section{LBP:}

Fig(4): VAS score in study groups.

There was significant decrease in LBP score in both groups from the preprocedure score (P-value<0.001). Patients in group 1 had less LBP score in comparison for group 2 (P-value $<0.001)$.

Table(3): LBP score in study groups.

\begin{tabular}{|l|l|l|l|}
\hline & Group 1 & Group 2 & p- value \\
\hline LBP(basal) & $18.65(3.15)$ & $19.1(2.43)$ & 0.62 \\
\hline LBP (2hour) & $14.65(2.25)$ & $15.05(3)$ & 0.64 \\
\hline LBP (1week) & $12.45(2.95)$ & $13.75(4.3)$ & 0.27 \\
\hline LBP (1month) & $\mathbf{8 . 1 5}(5)$ & $13.2(5)$ & $0.003 *$ \\
\hline LBP(3month) & $5.9(4.63)$ & $12.35(6.5)$ & $0.001 *$ \\
\hline
\end{tabular}

Data presented as Mean(SD). * P-value $<0.05$

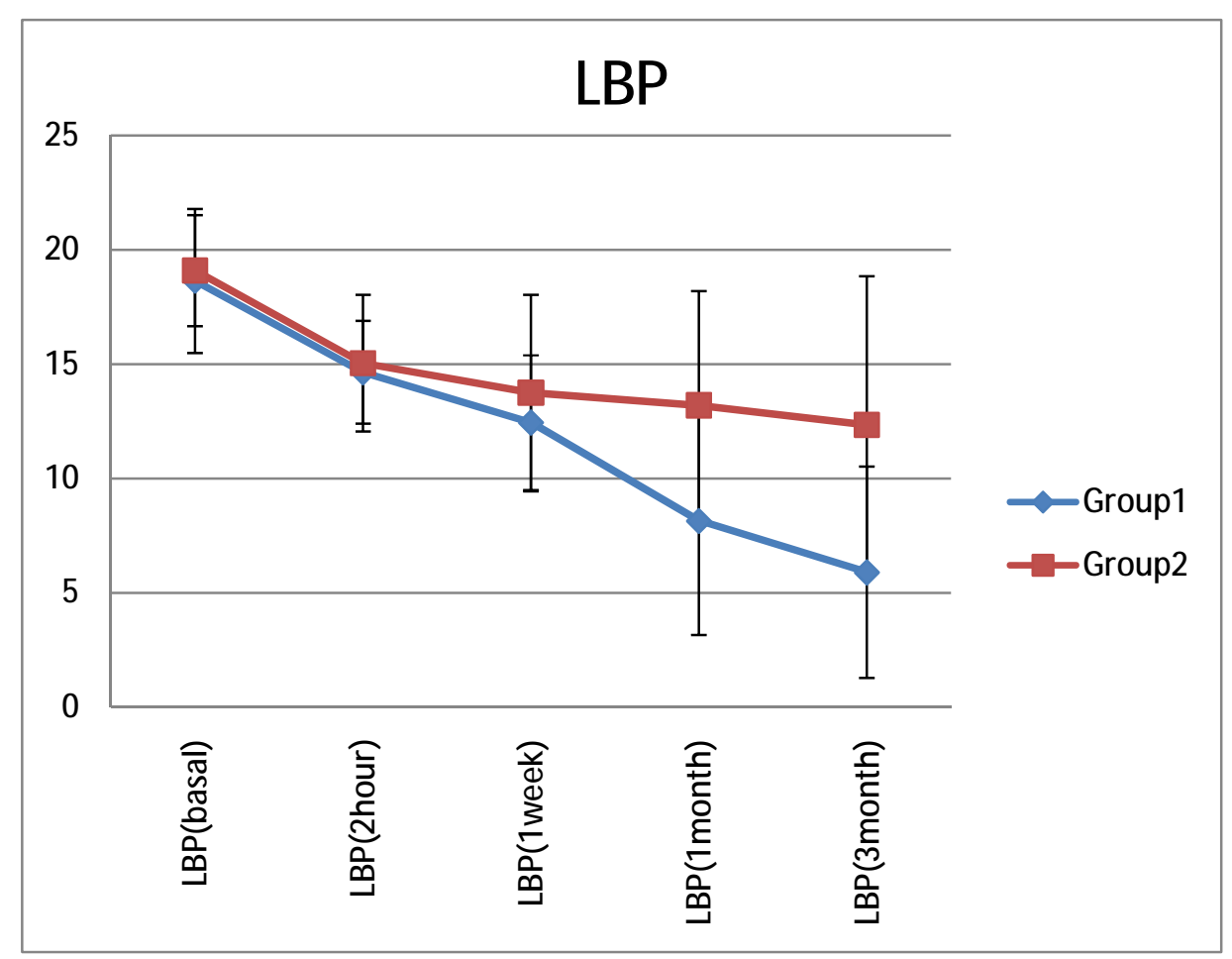

Fig(5)LBP score in study 


\section{Complication}

The patient in our study experience no major complication as regards Subarachnoid injection, Arterial injection of steroids, Side effects of the RF, such as increase in pain, sensory impairment, Paralysis/paresis and Infection. But there are some other minor complications: Direct trauma to the exiting nerve root or the spinal cord ( 6 cases . also Complication related to the procedure as Dysesthesiae

\section{discussion}

In our study, we evaluated the comparative effectiveness of TFESI versus PRF for the treatment of lumbosacral radicular pain. The Evaluation parameters for the both groups including pain evaluation (visual analogue scale VAS (0-10), low back pain questionnaire), consumption of analgesic drugs, patient satisfaction and reporting of possible complications. All the previous parameters are evaluated pre and post the procedure ( $2 \mathrm{hrs}$ after the procedure, after one $1^{\text {st }}$ week, after one month and after 3 months from the procedure) .

\section{Pain Scores (TFESI):}

The results of this study indicated that there was significant decrease in VAS score in both groups from the pre procedure score. Patients in TFESI group had less VAS scores in comparison for PRF group . after one week, after 1 month and after three months .

Riew and co workers showed results similar to our study as regard steroid group, They demonstrated the effectiveness of transforaminal epidural corticosteroids in subjects with disc herniations and/or spinal stenosis. Their study included patients with disc herniations or spinal stenosis referred for surgical evaluation. All subjects had clinical indications for surgery, and radiographic confirmation of nerve root compression. They concluded that selective nerve root injections of corticosteroids were efficacious in helping otherwise excellent candidates for spine surgery to avoid an operation. They also conclude that selective nerve root injections might be effective because they provided more focal delivery of corticosteroids to the compressive nerves than other types of epidural injections. Their study also showed that the first injection had the greatest impact on symptoms, with subsequent injections having less effect. The injections appear to provide benefit for patients with both acute and chronic complaints (Riew et al., 1999 ) .

Also Kumar and colleagues showed results similar to our study as they demonstrated that fluoroscopically guided TFESI was effective at alleviating radicular pain and reducing need for surgery (Kumar $\mathbf{N}$ et al., 2008 ).

Contradictory to the results in the current study, Hildebrandt, cited that epidural steroid injections might not be effective. The benefits of epidural steroid injections seem to be of short duration only. Furthermore, it is unclear which patients benefit from these injections (Hildebrandt, 2001). Review articles and literatures have failed to demonstrate evidence of therapeutic superiority for transforaminal injection (STAAL, et al., 2009).However,these contradictory results can be attributed to patient selection criteria as in the current work all patients had radicular pain for more than 6 months.

Also Vad found TFESIs to be superior to paraspinal saline trigger point injections for radicular symptoms from HNP (Vad VB, Et al., 2002) . 
Karppinen et al found a single TFESI with methylprednisolone and bupivacaine to be superior for leg pain in subjects with unilateral lumbar radiculopathy ( KARPPINEN et al., 1967).

Manchikanti and others compared the three routes of epidural steroid injections in the management of chronic low back pain. The study design included three groups: Group I, which received interlaminar epidurals with a midline approach in the lateral position, with entry between L3/4 or L4/5 in nonsurgical patients and above the scar either at $L 2 / 3$ or $L 1 / 2$ in postsurgical patients, using a loss-ofresistance technique; Group II, which received caudal epidurals, the procedures being performed in prone position, under fluoroscopy with confirmation of the position by injection of contrast; and Group III, which received transforaminal epidural corticosteroid injections, using either sacral or lumbar transforaminal technique under fluoroscopy. The results of the study showed that all three routes of administration of epidural corticosteroid administration were clinically effective, though administration by caudal and transforaminal routes was more successful in obtaining longer term relief. Further, this study also showed that the transforaminal injections were the ideal, as the most significant improvement was noted with the least expense compared to the caudal epidural, and to interlaminar epidural without the use of fluoroscopy (Manchikanti L. et al. 1999).

Devulder also studied transforaminal epidural injections, which he termed nerve root sleeve injections with corticosteroids; however, they were combination with hyaluronidase. Devulder reported that $55 \%$ of the patients reported greater than 50\% relief at 1 month, while $50 \%$ of the patients experienced continued relief after 3 months ( Devulder, J., 1998 ).

Emre Adigüzel and colleagues concluded that TFESI is effective in pain management of radicular LBP in the mid-term. The results of this study show that TFESI is effective not only in pain reduction but also in the improvement of activities of daily living (Emre et al., 2017).

Also Vad and associates reported that The success rate was found to be in the transforaminal anterior epidural steroid injection group, whereas it was decreased the placebo group (Vad VB et al., 2002 ).

Also In a study by Botwin et al., on patients who underwent fluoroscopyguided transforaminal anterior epidural steroid injection, they found that there was at least a $50 \%$ decrease in VAS scores of $75 \%$ of the patients during a 6-week follow up period (Botwin KP et al., 2002).

Derby and colleagues correlated surgical outcome with pain relief following transforaminal epidural injections with local anesthetic and steroids and reported that patients who fail to obtain sustained relief of radicular pain following the block were less likely to benefit from subsequent surgical intervention (Derby $\mathbf{R}$ et al., 1992).

\section{Pain Scores (PRF):}

The results of our study indicated that there was significant decrease in VAS score in PRF groups from the pre procedure score but the pain improvement lesser than the steroid group.

In our study a parameter used in PRFT was as follow: the current lesion applied was for $20 \mathrm{~ms}$, at $2 \mathrm{~Hz}$, for 120 second. A maximum temperature was $42^{\circ} \mathrm{C}$. Sensory stimulation $(50 \mathrm{~Hz})$ threshold was under 0.6 volts which made paresthesia in the usual distribution of radicular pain while 
Motor stimulation was at $2 \mathrm{HZ}$ caused weak muscle contraction at target nerve. The stimulation was above 2 volts to ensure that the probe was far away from ventral horn cell and so close to DRG.The Impedances was about 300 Ohms. For selective nerve root block, the volume was 1.0- 1.5 $\mathrm{mL}$ (both $2 \%$ lidocaine and $40 \mathrm{mg}$ of methylprednisolone acetate).

In accordance with this study Teixeira and others found that the PRF treatment adjacent to the ganglion spinale (DRG) of the nerve involved improves the radicular pain ( Teixeira A et al., 2005).

Also Bozem et al. reported that $55 \%$ patients with chronic intractable lumbosacral radicular showed substantial pain improvements at 6 months after PRF (Choi GS et al., 2012).

Choi et al. reported that application of PRF is useful intervention for lumbar radicular pain (Chao et al. 2008).

\section{Pain Scores (TFESI Vs PRF):}

The results of our study indicated that there was significant decrease in VAS score in both groups from the pre procedure score. Patients in TFESI group had less VAS scores in comparison for PRF group . after one week ,after 1 month and after three months .

Lee DG and colleagues compared the effectivenesses of pulsed radiofrequency (PRF) administered to a targeted dorsal root ganglion (DRG) and TFESI for the treatment of radicular pain due to disc herniation. They found that Mean VAS scores for cervical and lumbar radicular pain were significantly lower 12 weeks after treatment in both study groups. However, no statistically significant difference was observed between the PRF and TFESI (Wonuk, et al., 2015)

Koh W and others reported that the combined application of PRF and
TFESI achieved higher treatment efficacies than TFESI alone in patients with chronic refractory radicular pain. These encouraging outcomes for the treatment of chronic radicular pain might suggest central sensitization can be modulated by suppressing glia activity in the dorsal horn (Koh W, et al. 2015).

On the other hand Lee and others shows that the clinical outcomes of patients treated with PRF for radicular pain was not inferior to those treated by TFESI at 3 months after treatment, and that TFESI and PRF both have significant treatment effects. Thus, their study subjects might have exhibited incomplete suppression of inflammation around DRGs and spinal nerves after 1st TFESI, which we believe may have produced similar outcomes in the two groups. Disc herniation increases potential for generating ectopic discharges at dorsal root ganglion, which produces central sensitization. As $1^{\text {st }}$ TFESI partially suppressed inflammation around the nerve and epidural space, central sensitization at DRG and dorsal horn of spinal cord was processing, which could explain no inferior effectiveness of PRF at DRG comparing to additional TFESI (Koh W, et al. 2015).

On the hand Koh and others reported that the combined appliation of PRF and TFESI achieved higher treatment efficacies than TFESI alone in patients with chronic refractory radicular pain (Koh W et al. 2015 ).

\section{Analgesic Drug Consumption}

At the baseline, all the patients were being treated with analgesic drugs (NSAIDs, opioids, and neuromodulators), yet by three month visit after treatment, patients in steroid group had decreased their consumption of analgesics with respect to the baseline levels more than 
decrease in PRF group. ,"( Trinidad et al,. 2015)

\section{Qulity of life}

Sithapan and others compared the effect of PRF combined with transforaminal epidural steroid injection (TFESI) to TFESI alone on CLRP. And concluded that Quality of life indicators improved from baseline in both groups, however no significant intergroup difference was found (Sithapan et al., 2016).

\section{Complications}

the adverse effects of TFESI raise safety issues. The majority of these adverse effects concern the administration of steroid and contrast media. The procedural side effects of steroid administration include facial flushing, and transient headaches (Engel A, et al. 2104 ).

Catastrophic adverse events have also been reported, even when TFESI is conducted by well trained physicians, the injection of particulate steroid into an artery around the spinal canal can occlude capillaries and arterioles and cause spinal cord and cerebellar infarction resulting in permanent motor and sensory deficits. In our study no patients had complained of these side effects (Baker R, et al 2003) .

The majority of studies conducted on the PRF for the treatment of radicular pain have reported no serious adverse events, but several authors have reported flare up of pain or temporary pain aggravation. In this study no patient experienced such side effects (Cohen SP, et al 2015).

$\mathrm{Vad}$ and others reported that complication rates of epidural steroid injection vary from $0 \%$ to $9.65 \%$; some of these complications were very serious in nature. Selective nerve root block appears to provide short-term improvement, but a subsequent rebound effect can develop. The transforaminal approach is very target specific, using the smallest amount of injectate possible to reach the primary site of pathology ( Vad et al., 2002). Geurts et al cited that both selective epidural and PRF have very low complications and adverse events rates (Geurts et al., 2003).

The current study states the safety of both used techniques for treatment of radicular pain. Geurts et al cited that there were no obvious differences regarding to adverse events and complications between selective epidural and PRF techniques. However, some complications were reported such as elevation of blood glucose level in diabetic patients, weakness in the lower limbs and numbness for a short period, but there were no permanent neurologic deficits or serious problems. There were no neurological deficits or adverse painful side effects from PRF apart from burning back pain during the first week in many cases. Thus, selective steroid injection (SNSI) and pulsed radiofrequency treatment of DRG are considered as effective procedures for treating chronic pain (Geurts et al., 2003).

In accordance to our results, Van Zundert et al., reported that many studies showed both safety and potential efficacy for PRF in the treatment of lumbar radicular pain, emphasizing its nondestructive nature. These findings are reliable with the previous data of Van Zundert et al (Van Zundert et al., 2003) in using PRFL for treatment of the cervical DRG. They imply that the use of PRFL in treatment of lumbar DRG is safe and effective (SIMOPOULOS, et al., 2008).

On the other hand Lee DG and others found that application of PRF temporary aggravates radicular pain, which subsided after several days. Although PRF is a less destructive procedure than conventional radiofrequency treatment and does not 
cause neurologic deficits, PRF can cause microscopic neuronal damage, endoneural edema, and pathologic changes in myelin, possibly due to the heat generated at the electrode tip. They presume that these effects could explain the temporary aggravation of radicular pain experienced on occasion (Lee DG, et al. 2016).

Shabat et al. found that the use of PRFDRG is save with no reported complication and PRF is a safe and an effective procedure for patients who suffer from chronic neuropathic pain from spinal origin (Shabat S,et al. 2006).

Simopoulous et al. stated that application of the PRF for lumbosacral radicular pain is with no side effects (Simopoulos TT. et al. 2008).

Choi et al. reported that application of PRF is safe intervention for lumbar radicular pain (Chao et al. 2008).

\section{Conclusion}

In this study, we aimed to present the effectiveness of Transforaminal Nerve Roots Steroid Injections Versus Pulsed Radiofrequency Application For Treatment of Chronic Low Back Pain. We found that there was significant

\section{References}

1-Riew KD, Yin Y, Gilula L et al. Can nerve root injections obviate the need for operative treatment of lumbar radicular pain? A prospective, randomized, controlled, double-blind study. Proceedings of North American Spine Society 16th Annual Meeting. Chicago, 1999, pp 94-95.

2-Lutz GE, Vad VB, Wisneski RJ. Fluoroscopic transforaminal lumbar epidural steroids: An outcome study. Arch Phys Med Rehabil 1998; 79:1362-1366.

3-Devulder, J. Transforaminal nerve root sleeve injection with corticosteroids, hyaluronidase, and local anesthetic in decrease in VAS score in both groups from the pre procedure score. Patients in TFESI group had less VAS scores in comparison for PRF group, and application of PRF is more safe than steroid injection

\section{RECOMMENDATIONS}

Transforaminal Nerve Roots Steroid Injection is more effective as Pulsed Radiofrequency Application For Treatment of Chronic Low Back Pain. Finally Pulsed Radiofrequency Application can be used as an alternative Transforaminal Nerve Roots Steroid Injection when there are contraindications to steroid injection .

\section{Limitations}

- Limitation is the follow-up duration of 3 months whereas PRF effects have been claimed to last up to 12 months in some studies. Therefore, we have no data on PRF's longer-term effects, which could be interesting to investigate in future studies. Also absence of a third group that had both PRF and ESNI it may be better. This study measured changes in low back pain using VAS, which is subjective and may introduce bias.

the failed back surgery syndrome. $J$ Spinal

Disord 1998;11:151-154.

4-Derby R, Kine G, Saal JA et al. Response to steroid and duration of radicular pain as predictors of surgical outcome. Spine 1992;17 (Suppl):176183

5-Teixeira A, Grandinson M, Sluijter $M$. Pulsed radiofrequency for radicular pain due to a herniated intervertebral disc_an initial report. Pain Prac. 2005;5:111-115.

6-Choi GS, Ahn SH, Cho YW, Lee DG. Long-term effect of pulsed radiofre- 
quency on chronic cervical radicular pain refractory to repeated transforaminal epidural steroid injections. Pain Med 2012; 13: 368-75.

7-Koh W, Choi SS, Karm MH, Suh JH, Leem JG, Lee JD, Kim YK, Shin J. Treatment of chronic lumbosacral radicular pain using adjuvant pulsed radiofrequency: a randomized controlled study. Pain Med 2015; 16 : 432-41.

8-Baker R, Dreyfuss P, Mercer S, Bogduk N. Cervical transforaminal injection of corticosteroids into a radicular artery: a possible mechanism for spinal cord injury. Pain 2003; 103: 211-5.

9-Cohen SP, Peterlin BL, Fulton L, Neely ET, Kurihara C, Gupta A, Mali J, Fu DC, Jacobs MB, Plunkett AR, et al. Randomized, double-blind, comparative-effectiveness study comparing pulsed radiofrequency to steroid injections for occipital neuralgia or migraine with occipital nerve tenderness. Pain 2015; 156: 2585-94.

10-Engel A, King W, MacVicar J; Standards Division of the International Spine Intervention Society. The effectiveness and risks of fluoroscopically guided cervical transforaminal injections of steroids: a systematic review with comprehensive analysis of the published data. Pain Med 2014; 15: 386-402.

11-Govind J: Lumbar radicular pain. Aust Fam Physician 2004, 33:409-412.

12- Thelander U, Fagerlund M, Friberg S, Larsson S: Straight leg raising test versus radiological size, shape and position of lumbar disc hernias. Spine 1992, 17:395-399.

13-McCarron RF, Wimpee MW, Hudkins PG, Laros GS: The inflammatory effect

of nucleus pulposus: a possible element in the pathogenesis of low back pain. Spine 1987, 12:760-764.
14-Olmarker K, Blomquist J, Stromberg J, Nanmark U, Thomsen P, Rydevik Inflammatogenic properties of nucleus pulposus. Spine 1995, 20:665-669.

15- Barnsley L: Steroid injections: effect on pain of spinal origin. Best Pract Res

Clin Anaesthesiol 2002, 16:579-596.

16-Saal JA, Saal JS, Herzog RJ: The natural history of lumbar intervertebral disc extrusions treated nonoperatively. Spine 1990, 15:683-686.

17-Lee HM, Weinstein JN, Meller ST, et al. The role of steroids and their effects on phospholipase A2: An animal model of radiculopathy. Spine 1998;23.

18- Kushnerik V, Altman G, Gozenput P: Pharmacology of steroids used during epidural steroid injections. Tech Reg Anesth Pain Manag 2009, 13:212-216.

19-Benedetti E, Siriwetchadarak R, Stanec J, Rosenquist R: Epidural steroid injections: Complications and management. Tech Reg Anesth Pain Manag 2009, 13:236-250.1191-6

20-Renfrew DL, Moore TE, Kathol MH, et al. Correct placement of epidural steroid injection: Fluoroscopic guidance and contrast administration. Am J Neuroradiol 1991;12:1003-7.

21- O’Neill C, Derby R, Knederes L. Precision injection techniques for the diagnosis and treatment of lumbar disc disease. Semin Spine Surg 1999; 11:104-18.

22-Derby R, Bogduk N, Kine G. Precision percutaneous blocking procedures for localizing spinal pain: Part 2. The lumbar neuraxial compartment. Pain Dig 1993;3:17588.

23- El Abd O, Amadera J, Pimentel DC, Gomba L. Immediate and acute adverse effects following transforaminal epidural steroid injections with 
SOHAG MEDICAL JOURNAL Transforaminal Nerve Roots Steroid Injections Versus Pulsed

dexamethasone. Pain Physician 2015. 18: 277-86.

24-Ahadian FM: Pulsed radiofrequency neurotomy: advances in pain medicine. Curr Pain Headache Rep 2004, 8:34$\underline{40}$

25- Higuchi Y, Nashold BS Jr, Sluijter M, Cosman E, Pearlstein RD. Exposure of the dorsal root ganglion in rats to pulsed radiofrequency currents activates dorsal horn lamina I and II neurons. Neurosurgery 2002; 50: 8505.

26-Hamann W, Abou-Sherif S, Thompson S, Hall $S$. Pulsed radiofrequency applied to dorsal root ganglia causes a selective increase in ATF3 in small neurons. Eur J Pain 2006: 10: 171-6

27-Simopoulos TT, Kraemer J, Nagda JV, Aner M, Bajwa ZH: Response to pulsed and continuous radiofrequency lesioning of the dorsal root ganglion and segmental nerves in patients with chronic lumbar radicular pain. Pain Physician 2008, 11:137-144.

28-Shabat S, Pevsner Y, Folman Y, Gepstein R: Pulsed radiofrequency in the treatment of patients with chronic neuropathic spinal pain. Minim Invasive Neurosurg 2006, 49:147-149.

29-Chao SC, Lee HT, Kao TH: Percutaneous pulsed radiofrequency in the treatment of cervical and lumbar radicular pain. Surg Neurol 2008,70:59-65

30-Lee, Dong Gyu, Sang-Ho Ahn, and Jungwon Lee. "Comparative Effectivenesses of Pulsed Radiofrequency and Transforaminal Steroid Injection for Radicular Pain due to Disc Herniation: a Prospective Randomized Trial." Journal of Korean Medical Science 31.8 (2016): 13241330.

31- Koh W, Choi SS, Karm MH, Suh JH, Leem JG, Lee JD, Kim YK, Shin J. Treatment of chronic lumbosacral radicular pain using adjuvant pulsed radiofrequency: a randomized controlled study. Pain Med 2015; 16 : 432-41. 39.

32- Koh W, Choi SS, Karm MH, Suh JH, Leem JG, Lee JD, Kim YK, Shin J. Treatment of chronic lumbosacral radicular pain using adjuvant pulsed radiofrequency: a randomized controlled study. Pain Med 2015; 16 : 432-41.

33-T. T. Simopoulos, J. Kraemer, J. V. Nagda, M. Aner, and Z. H. Bajwa, "Response to pulsed and continuous radiofrequency lesioning of the dorsal root ganglion and segmental nerves in patients with chronic lumbar radicular pain," Pain Physician, vol. 11, no. 2, pp. 137-144, 2008.

34-Choi GS, Ahn SH, Cho YW, Lee DG. Long-term effect of pulsed radiofrequency on chronic cervical radicular pain refractory to repeated transforaminal epidural steroid injections. Pain Med 2012; 13: 368-75.

35-Vad VB, Bhat AL, Lutz GE, Cammisa F. Transforaminal epidural steroid injections in lumbosacral radiculopathy: a prospective randomized study. Spine 2002; 27: 116.

36-Kumar N, Gowda V. Cervical foraminal selective nerve root block: a 'two-needle technique' with results. Eur Spine J 2008; 17: 576-84.

37-Adigüzel, Emre, et al. "The effectiveness of transforaminal epidural steroid injection in patients with radicular low back pain: Combination of pain provocation with effectiveness results." Turkish Journal of Physical Medicine and Rehabilitation 63.2 (2017).

38-Kikuchi Y. Higuchi, B. S. Nashold Jr., M. Sluijter et al., "Exposure of the dorsal root ganglion in rats to pulsed radiofrequency currents activates dorsal horn lamina I and II neurons," 
SOHAG MEDICAL JOURNAL Transforaminal Nerve Roots Steroid Injections Versus Pulsed

Neurosurgery, vol. 50, no. 4, pp. 850 856, 2002.

39-K. Van Boxem, J. Cheng, J. Patijn et al., "11. Lumbosacral radicular pain," Pain Practice, vol. 10, no. 4, pp. 339358, 2010.

40-Munjupong, Sithapan, Nuj Tontisirin, and Roderick J. Finlayson. "The Effect of Pulsed Radiofrequency Combined with a Transforaminal Epidural Steroid Injection on Chronic Lumbar Radicular Pain: A Randomized
Controlled Trial." Advances in Anesthesiology 2016 (2016).

41-Koh, Wonuk, et al. "Treatment of chronic lumbosacral radicular pain using adjuvant pulsed radiofrequency: a randomized controlled study." Pain Medicine16.3 (2015): 432-441. 